\title{
Exploring the role of smartphone technology for citizen science in agriculture
}

\author{
Katharina Dehnen-Schmutz ${ }^{1}$ (D) - Gemma L. Foster ${ }^{1} \cdot$ Luke Owen $^{1} \cdot$ Séverine Persello $^{2,3}$
}

Accepted: 16 March 2016/Published online: 8 April 2016

(C) The Author(s) 2016. This article is published with open access at Springerlink.com

\begin{abstract}
Citizen science is the involvement of citizens, such as farmers, in the research process. Citizen science has become increasingly popular recently, supported by the proliferation of mobile communication technologies such as smartphones. However, citizen science methodologies have not yet been widely adopted in agricultural research. Here, we conducted an online survey with 57 British and French farmers in 2014. We investigated (1) farmer ownership and use of smartphone technologies, (2) farmer use of farmspecific management apps, and (3) farmer interest and willingness to participate in agricultural citizen science projects. Our results show that $89 \%$ respondents owned a smartphone, $84 \%$ used it for farm management, and $72 \%$ used it on a daily basis. Fifty-nine percent engaged with farm-specific apps, using on average four apps. Ninety-three percent respondents agreed that citizen science was a useful methodology for data collection, $93 \%$ for real-time monitoring, $83 \%$ for identification of research questions, $72 \%$ for experimental work, and $72 \%$ for wildlife recording. Farmers also showed strong interest to participate in citizen science projects, often willing to commit substantial amounts of time. For example, $54 \%$ of British respondents were willing to participate in farmland
\end{abstract}

The original version of this article was updated due to a retrospective Open Access order. The erratum is available under DOI 10.1007/ s13593-017-0451-9.

Katharina Dehnen-Schmutz

ab6340@ coventry.ac.uk

1 Centre for Agroecology, Water and Resilience, Coventry University, Ryton Gardens, Wolston Lane, Coventry CV8 3LG, UK

2 Bordeaux Sciences Agro, 1, cours du Général de Gaulle CS 40201, 33175 Gradignan Cedex, France

3 Present address: CIRAD, UPR HortSys, 97455 Saint-Pierre Cedex, Réunion Island, France wildlife recording once a week or monthly. Although financial support was not always regarded as necessary, experimental work was the most likely activity for which respondents thought financial support would be essential. Overall, this is the first study to quantify and explore farmers' use of smartphones for farm management, and document strong support for farm-based citizen science projects.

Keywords Citizen science · Smartphones $\cdot$ Farm management applications $\cdot$ Britain $\cdot$ France $\cdot$ Participatory research

\section{Introduction}

Non-professional people (lay persons/amateurs/volunteers) have participated in scientific research for several centuries, often contributing profound subject knowledge (Silvertown 2009; Pescott et al. 2015). The involvement of volunteers in research is now commonly referred to as "citizen science", with recent years seeing a rapid increase in the number of citizen science initiatives available globally, particularly in Europe and North America (Silvertown 2009). Topics for research are diverse, and examples include the observation of weather patterns, or the recording of plants and animals (Dickinson et al. 2010).

Recent advances in digital information and communication technologies have enabled much wider participation in citizen science, to include people that may not possess any, or only limited, background knowledge of the studied subjects, but are nevertheless willing to contribute by collecting data (Adriaens et al. 2015; Graham et al. 2011; August et al. 2015). Furthermore, the development of mobile smartphone technologies in particular offers several advantages, including the functionality to take photographs, use microphones and 
recording software, and access geographical information and global positioning systems (GPS) (Teacher et al. 2013).

Smartphones that have an Internet connection, and a touchscreen or something similar as an interface, are now very widely used and have become embedded into contemporary societies throughout much of the world. Indeed, it is estimated that globally, two billion people own a smartphone, and that by $2020,80 \%$ of the global population will do so (The Economist 2015). In the UK, $66 \%$ of the adult population owned a smartphone in the first quarter of 2015, an increase of $27 \%$ since 2012 (OFCOM 2015), and in France, $58 \%$ people owned a smartphone in 2015, an increase of $12 \%$ since 2014 (CRÉDOC 2015). As owners carry these devices around almost constantly, they are also on standby to record observations, or to access dedicated applications (from here on referred to as apps) designed specifically for citizen science projects in app stores such as Google Play and iTunes, without the need for special preparations and equipment. Consequently, the availability of smartphone apps developed for citizen science projects has increased in recent years. However, few citizen science projects are targeted at farmers or explore agricultural research questions.

Although there are a large number of apps available to support farmers, only a limited number utilise smartphone built-in sensors to provide agricultural solutions (Pongnumkul et al. 2015). The majority of apps currently available are designed by commercial companies, usually providing information or services in a unidirectional linear flow, from the developer to the user. In contrast, citizen science apps are designed to be more collaborative and participatory, and tend to be developed by charities, scientific or academic institutions, and government departments. Crucially, they allow the user to submit information to the developer, often receiving feedback in return. This feedback can range from a simple acknowledgment of the record received, to more detailed project-related information, such as the confirmation of species identifications.

One of the few examples of citizen science apps promoted to farmers is the MyPestGuide apps (Fig. 1), developed by the Department of Agriculture and Food, Western Australia (DAFWA, https://www.agric.wa.gov.au/pests-weedsdiseases). These apps encourage farmers (and members of the public) to send reports and photographs of suspected plant diseases and pests directly to the DAFWA, to enable experts to identify the species, provide feedback, and map the record. In this sense, apps such as the MyPestGuide apps contribute to farmers achieving cost-effective precision agriculture outcomes and contribute to a broader evidence base about the prevalence of certain species.

The lack of citizen science projects aimed at farmers is surprising, because farmers are known to take part in participatory research projects, and they are well placed to gather environmental data (the focus of many citizen science initiatives).

Traditionally, farm-based participatory research has taken the form of farm trials or networks, with data being collected through

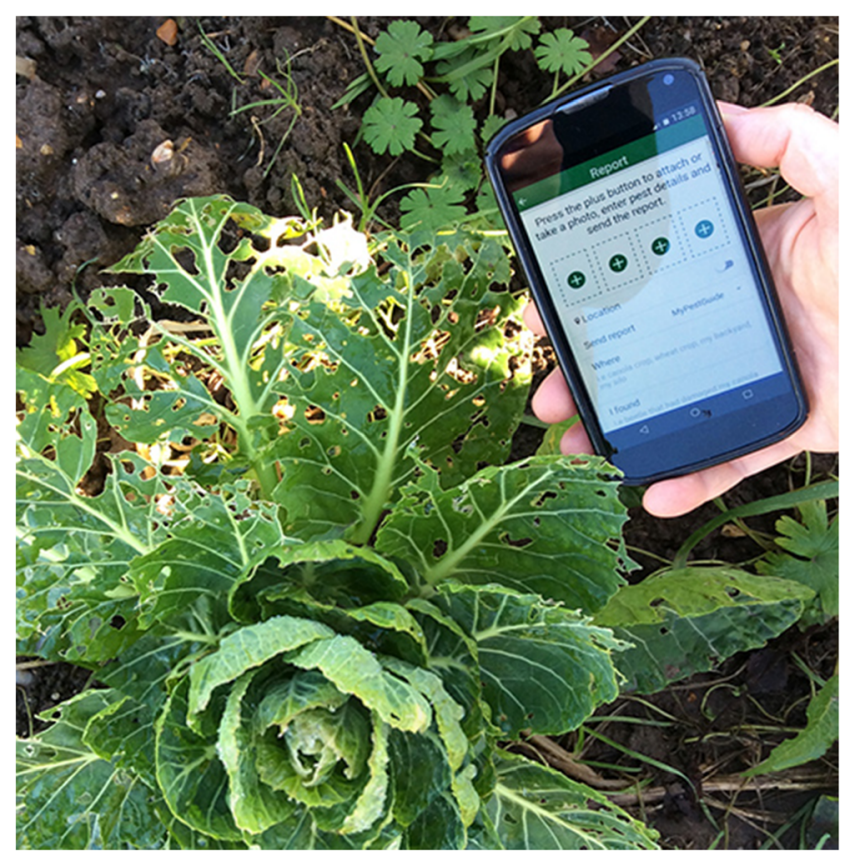

Fig. 1 Smartphone applications developed for farm management include applications designed to identify and report pests, including photographs and locations helping farmers to identify the pests and researchers to collect data. Shown here is the MyPestGuide app developed by the Department of Agriculture and Food, Western Australia

farm visits, crop assessments, farm records, and farmer interviews - an approach which makes data collection timeconsuming for researchers and farmers. Digital technology offers the opportunity to streamline this process, with smartphone apps offering great potential to collect data remotely and efficiently.

Agricultural and farming topics are increasingly being discussed through interactive online social media spaces (e.g. Twitter, Facebook, YouTube). For example, the not-for-profit organisation AgriChatUK has been hosting weekly discussions related to the UK farming industry since 2012 via Twitter (@ AgriChatUK). At present, AgriChatUK has over 17,500 Twitter followers, and it has become an established forum for lively debate, problem solving, knowledge exchange, and networking amongst industry stakeholders. Farmers are also known to take part in participatory research projects involving small groups of farmers getting together in "Farm Labs" (MacMillan and Pearce 2014) or "Monitor Farms" (Prager and Thomson 2014) to work on specific problems. These projects demonstrate that farmers are generally willing to participate in collaborative research ventures and may therefore also be interested in larger scale citizen science projects exploring agricultural research questions. However, as the success of these larger projects often depends on a sufficient number of users with access to smartphone technologies, this technological need could be perceived as an obstacle for use in agriculture. This is because at present, there is no data available on the current scope or potential for smartphone use and farm-specific apps by farmers. 
In this study, we bridge this gap. The aim of our study was to conduct a survey with farmers to gather novel data about (i) their use of smartphone technologies, (ii) their use of farmspecific management apps, and (iii) their interest in, and willingness to participate in, agricultural citizen science projects. This paper is the first to quantify and explore farmers' use of smartphones in Europe and assess the potential of smartphones for farm-based participatory research.

\section{Materials and methods}

The online survey was conducted in Britain and France as a result of an exchange collaboration between the Centre for Agroecology, Water and Resilience at Coventry University, UK, and the Bordeaux Sciences Agro, France. A multicountry approach was used to reflect the European Union funding and research landscape, as funding instruments like the Horizon 2020 programme and the European Innovation Partnership for Agricultural Productivity and Sustainability (EIP-AGRI), increasingly encourage or specify transnational research projects, in which multi-actor activities build bridges between practitioners and researchers.

\subsection{Survey design and distribution}

The survey was built in an English and a French version using the web survey development service of Bristol Online Survey (https://www.onlinesurveys.ac.uk/). The questionnaire consisted of 27 questions, structured into four sections: smartphone usage, app usage, farmers' interest to participate in citizen science projects, and information/profile data about the respondents. These four sections are now briefly outlined:

\section{Section 1: Smartphone usage}

The aim of this section was to explore farmers' engagement with smartphones, in context with their usage of other communication and information technologies for farm management. Participants were first asked if they had a smartphone, if they were using it for farm management, and for how long they had been doing so. Respondents who did not own or use a smartphone could still participate in the survey but were not required to answer the questions related to smartphone and app use. This section also contained questions about their use of other technologies, in particular about landline telephones, desktop computers, laptops, tablets, "basic" mobile phones (with no Internet connection), and the use of cameras and GPS on mobile devices. This enabled us to situate smartphone usage within the broader technological portfolio of farmers. We also asked if farmers were using social media, online resources, and printed magazines for farm management relevant purposes. If using smartphones, participants were asked to rank different uses (calls, texting, apps, camera, GPS) according to the frequency they were using them. We then asked participants to name any apps they were using for farm management.

Section 2: Applications (apps) used

In this section, we provided a list of farm management apps relevant to each country and asked participants if they knew about them, if they had installed them, and if they had, how often they were using them. To avoid any bias in the selection of apps, the list of apps presented were taken from articles in the popular farming press in both countries. For Britain, this was from the Farmers Weekly article "16 essential farm apps for 2014" (Farmers Weekly 2014), and for France from an Internet article recommending 14 apps in "le journal du web agricole" (accessed in June 2014). These articles introduced their selected apps as "some of the most useful apps covering arable, livestock, and general apps which are useful to all farmers" (Farmers Weekly 2014). This wide coverage was important as the survey was aimed at farmers from all types of farming. There was also an option to mention any other farm management apps not included in this list, or mentioned already in the previous section.

Section 3: Farmers' interest to participate in citizen science projects

This section was introduced with a short definition of citizen science ("Citizen science or crowdsourcing is an increasingly popular methodology for data collection or analysis, knowledge transfer, and identification of research needs. The key feature of citizen science is the involvement of volunteers in one or several of these research activities."). We then presented a list of potential activities (data collection, real-time monitoring, identifying research questions, experimental work, recording wildlife) and asked participants (i) to indicate their agreement that these would be useful purposes for citizen science in agricultural research, (ii) their potential interest to participate, (iii) their potential time commitment, and (iv) to what extent their potential commitment would depend on financial support. There was also an option to suggest further activities and to mention any previous citizen science projects they may have participated in.

Section 4: Information about the respondents

Ten questions covered characteristics of the respondents (gender, age, education) and their farms (ownership, location, farm type, size, labour).

Coventry University's ethics committee approved the survey. The English survey was launched on the 30th of June 2014 and the French survey on the 9th of July 2014, and both surveys closed after 5 months at the end of November 2014. This allowed sufficient time for the 
survey to be circulated by email within agricultural and farming networks and social media.

\subsection{Statistical analysis}

Data and statistical analysis was performed using R (R Core Team 2015) including the Likert package. All questions were analysed for French and British responses combined and tested for differences between them using Fisher's exact test for count data. If no significant differences were found between countries, the results are reported for the whole sample only.

\section{Results and discussion}

We received 60 responses in total. However, three responses were excluded because they were from respondents outside the two countries of this study. Thirty-seven responses were received from Britain and 20 from France, providing us with a sample of 57, on which statistical analysis was performed.

Table 1 shows some of the social characteristics of the respondents, their roles and farms. There was more than double the number of male (39) to female (18) respondents, with an average age of 43 years (range 18 to 74 ).

We found significant differences between British and French respondents in terms of qualifications, farm ownership, and type of farm (Table 1). In particular, British participants held higher qualifications ( 24 respondents with a degree or above) and were more likely to be farm owners, while most French participants were in the "tenant and owner" category. Mixed farming was the most popular category for French participants (6) followed by cereal farms (4), whereas in Britain cereal farmers were the largest group (8), followed by horticulture (7) - a category for which there was no French participant. In both countries, larger farms with more than 100 ha were the largest group, and there was no significant difference between the two countries.

Thirteen farms were managed organically, although in one case organic status only applied to certain parts of the farm. The mean fulltime labour equivalent was 2.1 but the range went up to 10 .

\subsection{Smartphone usage}

The majority of respondents used smartphones (89\%), with only six respondents reporting that they did not use a smartphone (four in Britain and two in France). This level of smartphone ownership is high when compared to the UK national average of $66 \%$ (OFCOM 2015). A survey of US farmers and ranchers carried out in 2014 by the American Business Media Agri Media Council, revealed that the majority of the farmers surveyed were not using smartphones
Table 1 Characteristics of British and French respondents and their farms. The significance of differences between the two groups was assessed with a two-tailed Fisher's exact test for categorical variables and a Kruskal-Wallis rank sum test for the continuous variables

\begin{tabular}{|c|c|c|c|}
\hline Variables & Britain & France & Total \\
\hline \multicolumn{4}{|l|}{ Gender n.s. $(p=0.092)$} \\
\hline Female & 15 & 3 & 18 \\
\hline Male & 22 & 17 & 39 \\
\hline \multicolumn{4}{|l|}{ Age n.s. $(p=0.4683)$} \\
\hline Mean (years) & 45 & 42 & 43 \\
\hline SD & 15.5 & 13.2 & 14.7 \\
\hline \multicolumn{4}{|l|}{ Qualifications* $(p<0.001)$} \\
\hline No qualification & 2 & 0 & 2 \\
\hline Apprenticeship & 1 & 3 & 4 \\
\hline GCSEs or equivalent & 2 & 2 & 4 \\
\hline A levels or equivalent & 6 & 2 & 8 \\
\hline Degree or above & 24 & 5 & 29 \\
\hline Other qualification & 2 & 2 & 4 \\
\hline Other & 0 & 6 & 6 \\
\hline \multicolumn{4}{|l|}{$\operatorname{Role}^{*}(p=0.005)$} \\
\hline Farm owner & 14 & 3 & 17 \\
\hline Tenant farmer & 8 & 3 & 11 \\
\hline Tenant and owner & 2 & 10 & 12 \\
\hline Farm manager & 5 & 1 & 6 \\
\hline Farm worker & 5 & 1 & 6 \\
\hline Other & 3 & 2 & 5 \\
\hline \multicolumn{4}{|l|}{ Type of farm* $(p=0.042)$} \\
\hline Cereals & 8 & 4 & 12 \\
\hline General cropping & 2 & 3 & 5 \\
\hline Horticulture & 7 & 0 & 7 \\
\hline Specialist pigs & 1 & 0 & 1 \\
\hline Specialist poultry & 4 & 2 & 6 \\
\hline Dairy & 5 & 2 & 7 \\
\hline Grazing livestock (less favoured areas) & 3 & 0 & 3 \\
\hline Grazing livestock (lowland) & 6 & 3 & 9 \\
\hline Mixed farming & 1 & 6 & 7 \\
\hline \multicolumn{4}{|l|}{ Farmsize n.s. $(p=0.060)$} \\
\hline$<5$ ha $(12 \mathrm{ac})$ & 7 & 1 & 8 \\
\hline $5<20$ ha $(12<49$ ac $)$ & 5 & 3 & 8 \\
\hline $20<50$ ha $(49<123 \mathrm{ac})$ & 4 & 0 & 4 \\
\hline $50<100$ ha $(123<247 \mathrm{ac})$ & 2 & 6 & 8 \\
\hline$>100$ ha $(>247 \mathrm{ac})$ & 19 & 10 & 29 \\
\hline \multicolumn{4}{|l|}{ Labour n.s. $(p=0.1035)$} \\
\hline Mean & 2.3 & 1.7 & 2.1 \\
\hline SD & 1.7 & 1.2 & 1.6 \\
\hline \multicolumn{4}{|l|}{ Organic n.s. $(p=0.554)$} \\
\hline Yes & 8 & 4 & 12 \\
\hline No & 29 & 15 & 44 \\
\hline Parts & 0 & 1 & 1 \\
\hline
\end{tabular}

*significant

n.s. non-significant 
(54\%) and or tablets (68\%) (Semler 2015). However, these figures are difficult to compare as our sampling method of recruitment through email and social media could be expected to attract survey responses from the more technologically informed famers. Nevertheless, similar to the American study, we also found that the younger respondents were more likely to own a smartphone, with smartphone owners in our survey being on average 42 years old, in contrast to the respondents who did not own smartphones, who were on average 56 years old. A Kruskal-Wallis rank sum test shows that this difference is significant (chi-squared $=5.77, \mathrm{df}=1, p$ value $=0.016$ ) . However, age is not always a reliable indicator, as the oldest respondent, a 74-year-old, had owned a smartphone for at least 3 years at the time of completing the survey.

Reasons given by the six participants who did not use smartphones included difficulties with access to suitable quality phone signals and Internet ("Poor phone signal, poor broadband connection so slow Wi-Fi"), operability of the devices ("Do not like complicated devices", "non-smartphone more able to withstand life on a holding"), as well as the perception that it was unnecessary ("I do not use it for work, and I do not need to make regular phone calls").

Poor mobile network coverage and broadband connectivity has been identified as an issue in rural areas in the UK in particular (Riddlesden and Singleton 2014), and the situation is likely to be similar in France. While network coverage can be expected to continually improve, Pongnumkul et al. (2015) conclude that apps would be most beneficial if they enable users to perform tasks while offline, and then synchronize with the appropriate databases once users have access to the Internet.

The majority of smartphone users in our survey had been using a smartphone for several years - 29 respondents (57\%) since 2012 and 16 respondents (31\%) since 2011. The phones used by respondents were relatively new, with 20 phones being less than a year old and 29 being between one and 3 years old. Just two phones were more than 3 years old. Operating systems used were mainly Apple iOS (24 respondents, $47 \%$ ) and Android (22 respondents, $43 \%$ ).

\subsection{Farm management}

Forty-eight respondents ( $84 \%$ of all respondents) were using a smartphone for farm management. The lack of time to investigate suitable applications for farm management was the reason most often mentioned by respondents who were not using their smartphone for farm management.

In comparison to other communication and information means, the smartphone was the device respondents used most often on a daily basis ( $72 \%$ ), only followed by desktop computers and laptops (used daily by 49 and $51 \%$, respectively). Landline phones were also still used frequently (35\% daily, $30 \%$ weekly) but some respondents reported no longer owning a landline phone (5\%) or never using it (4\%). Nonsmartphone mobile phones without Internet access or apps were still used on a daily basis by $18 \%$ of respondents, although the majority $(60 \%)$ did not have this sort of phone anymore, or were not using it (7\%). Unsurprisingly, given that we used social media as one tool to recruit respondents, we found that $63 \%$ of them were using social media daily or weekly in a farm management context, although around about a quarter of respondents did not access social media for this purpose. Printed and online media covering agricultural topics remained a popular source of information for farmers, being accessed by $49 \%$ of respondents at least weekly and a further $23 \%$ monthly. Although online resources were used by a greater proportion of respondents on a weekly basis $(68 \%)$, they were not used by $13 \%$ of respondents (compared to $11 \%$ not using printed media).

More specifically for smartphone use, when asked to rank different uses, making phone calls was ranked first by the majority of respondents (36 respondents, $71 \%$ ), followed by Internet access (ranked first by 13 respondents, $25 \%$ ) and texting (11 respondents, $22 \%$ ). Summing the responses within the first three ranks still confirmed making phone calls as the most frequent use (46 scores), followed by Internet access (34), texting (33), taking photographs (32), and the use of apps (31). Use of GPS was the least frequent activity receiving just 18 scores in the top three ranks.

\subsection{Use of applications on smartphones}

More than one-third of respondents (21) do not use any farmspecific apps on their smartphones for farm management. Respondents using apps named on average four apps that they used for farm management; however, this ranged from one to ten apps. This suggests that engagement with apps varies, although no significant differences could be detected between groups tested (see variables in Table 1). From the list of apps included (which was different for the two countries), only a few were used (Table 2), with the most popular in Britain being the Met Office weather app, which was used by more than $70 \%$ of participants in the British survey. No other app received comparable usage - the next most popular apps in Britain were weed spotter (34\% using), mySoil (30\%), and weather pro $(28 \%)$. The French list did not include any weather apps, and the most popular app here, used by $21 \%$ of respondents, was FNSEA developed by the French national federation of farmers' unions (Fédération Nationale des Syndicats d'Exploitants Agricoles, FNSEA) providing information and news about the unions and agriculture. In both countries, however, the majority of the apps included in the survey were unknown to most respondents, some were known but not installed or have been installed but were not used. The low engagement with some specific apps could be explained by the fact that our survey was not specific to any particular type 
Table 2 Farmers usage of farm management apps advocated in the farming press in Britain and France, respectively

\begin{tabular}{lrrrr|lrrrr} 
Britain & Using & Installed & Known & Unknown & France & & & & \\
App & Using & Installed & Known & Unknown \\
\hline Metoffice & 71.0 & 9.7 & 6.5 & 12.9 & FNSEA & 21.4 & 0.0 & 42.9 & 35.7 \\
WeedSpotter & 34.5 & 3.4 & 37.9 & 24.1 & YaraCheck & 13.3 & 0.0 & 20.0 & 66.7 \\
mySoil & 30.0 & 6.7 & 13.3 & 50.0 & Fertitest & 13.3 & 0.0 & 26.7 & 60.0 \\
Weatherpro & 27.6 & 3.4 & 20.7 & 48.3 & YaraImage & 12.5 & 0.0 & 25.0 & 62.5 \\
YaraCheck & 17.9 & 3.6 & 21.4 & 57.1 & Firestone & 6.7 & 0.0 & 6.7 & 86.7 \\
iLevel & 17.2 & 3.4 & 27.6 & 51.7 & Kuhn & 6.7 & 0.0 & 20.0 & 73.3 \\
Disease ID & 17.2 & 3.4 & 27.6 & 51.7 & ODA & 6.7 & 0.0 & 13.3 & 80.0 \\
Firestone & 10.7 & 7.1 & 14.3 & 67.9 & GoHarvest & 0.0 & 6.7 & 13.3 & 80.0 \\
Agrovista & 10.7 & 3.6 & 14.3 & 71.4 & TankCalc & 0.0 & 0.0 & 6.7 & 93.3 \\
StockMove & 7.4 & 0.0 & 7.4 & 85.2 & Spreading & 0.0 & 0.0 & 6.7 & 93.3 \\
GleadellMobile & 7.4 & 7.4 & 25.9 & 59.3 & Vicon & 0.0 & 0.0 & 6.7 & 93.3 \\
farmGRAZE & 3.6 & 0.0 & 21.4 & 75.0 & LienHorti & 0.0 & 0.0 & 13.3 & 86.7 \\
MooMonitor & 3.6 & 3.6 & 10.7 & 82.1 & HARDI & 0.0 & 0.0 & 6.7 & 93.3 \\
GoHarvest & 3.4 & 0.0 & 17.2 & 79.3 & Di@gnoPlant & 0.0 & 0.0 & 13.3 & 86.7 \\
TotalBovine & 0.0 & 3.8 & 3.8 & 92.3 & & & & & \\
Ross & 0.0 & 3.4 & 3.4 & 93.1 & & & & &
\end{tabular}

Figures shown are the percentages of respondents who are using the app (Using), having installed the app but are not using it (Installed), know the app but not installed (Known), and who do not know the app (Unknown). Apps in the list are for general use (Agrovista, Metoffice, mySoil, Weatherpro, FNSEA, ODA, LienHorti), arable (Di@gnoPlant, Disease ID, GleadallMobile, GoHarvest, Kuhn, WeedSpotter, YaraCheck, YaraImage), machinery (Fertitest, Firestone, Hardi, Spreading, TankCalc, Vigon), and livestock use (farmGRAZE, MooMonitor, Ross, StockMove, TotalBovine)

of farm business, and these apps may therefore not be relevant for farmers from different sectors taking part in the survey.

Additional apps mentioned by respondents include specific crop or livestock management apps (e.g. Practical Pig, Livestock Manager, Mobile Herd, T4CInHerd, Total Oilseeds, Hutchinsons Fieldwise, Geofolia), further apps for the identification of pests, diseases, and weeds (e.g. Pest spotter, Weed ID), and general farm management apps (Planimeter GPS, Arpentage GPS, GateKeeper mobile). Non-farm-specific apps, for example, for banking, shopping or communication, are also used for farm management.

\subsection{Citizen science for agricultural research}

Overall respondents were very positive about citizen science and regarded it a useful approach in agricultural research for all purposes outlined in the survey (see Fig. 2), but in particular for data collection and real-time monitoring. A majority of $83 \%$ of participants also agreed on the usefulness of the approach of involving farmers in the process to identify research questions. This result supports more recent trends in agricultural research where farmers and researchers work together to develop research programmes to deliver more sustainable solutions with higher rates of uptake by farmers (MacMillan and Pearce 2014; Doohan et al. 2010). Respondents were asked to suggest research topics for which they thought citizen science approaches could be useful. Topics named included variety trials, recording of sowing and planting dates, soil properties, outputs from farm renewable energy systems, and recording electronic individual animal identification (EID) data. A few participants had previous experience in participating in citizen science projects, and the projects mentioned include Project Splatter, a UK wide project to report road kill, the UK Duchy original future farming participatory project, yield recording projects, dietary studies, and bird monitoring.

When asked about their potential interest to participate in citizen science projects for each of the activities (Fig. 2), the majority of respondents were likely or very likely to participate. Given that no description of particular tasks or participation effort was specified, these are remarkably high scores, indicating great enthusiasm for citizen science in agricultural research. This enthusiasm is confirmed in the time respondents are willing to commit to the different activities (Fig. 3), which also corresponds well to the nature of these activities (i.e. higher frequency of time commitments for realtime monitoring and less frequent for experimental work).

Financial support was not always regarded as essential for participation in citizen science projects. It was not considered necessary by $30 \%$ of respondents for the identification of research questions, by $26 \%$ for real-time monitoring and wildlife recording, respectively, by $21 \%$ for data collection, and by $16 \%$ for experimental work. Experimental work was the most likely activity for which respondents thought financial support would be essential (37\%), probably because of the greater time commitments involved in establishing experiments and recording outcomes. Financial support was also regarded as essential for data collection by $18 \%$, for identifying research questions by $16 \%$, and for recording wildlife by $9 \%$. Responses to this question also revealed a high level of 
Positive

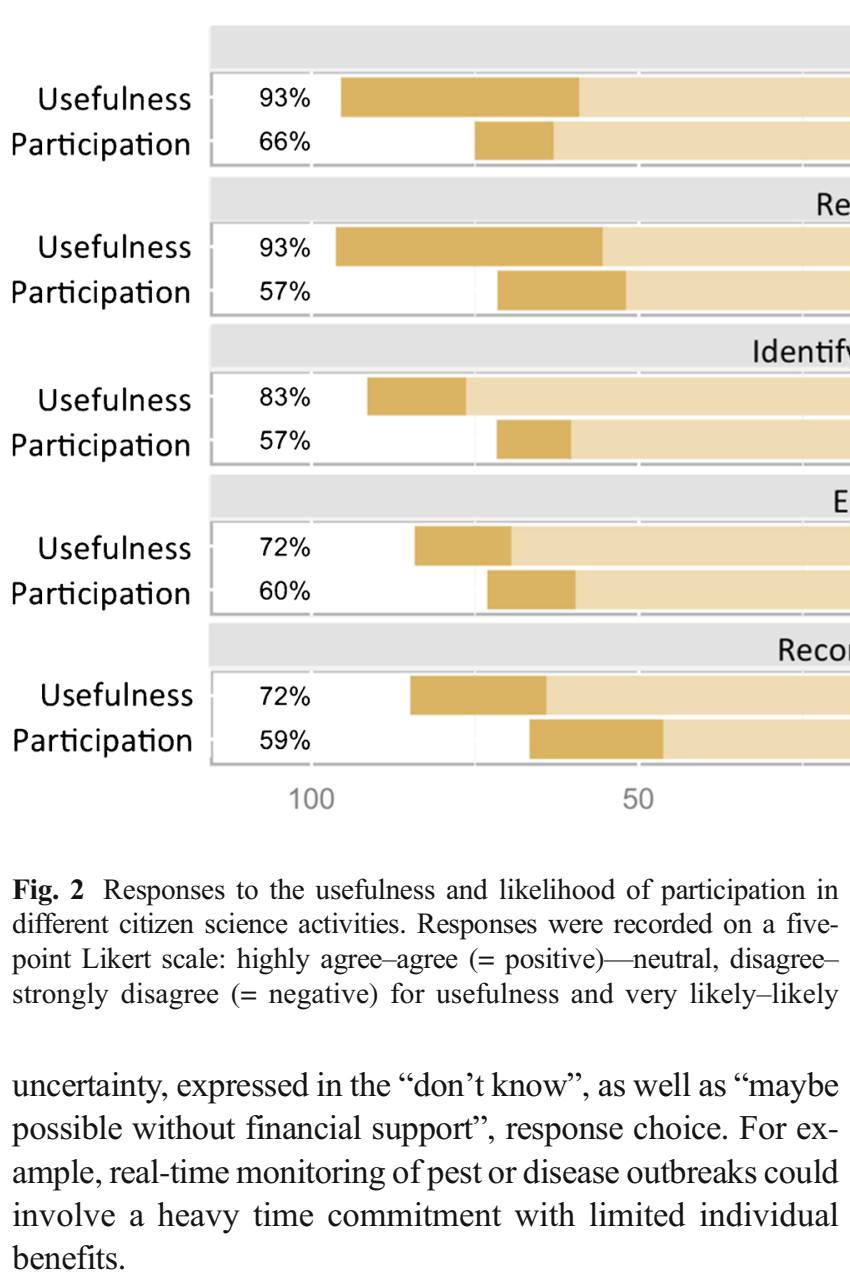

Neutral

Negative

\section{Collecting data}

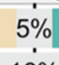

$18 \%$

Real-time monitoring

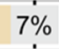

$29 \%$

$0 \%$

$14 \%$

search questions

$17 \%$

$30 \%$

$0 \%$

$13 \%$

Experimental work

$24 \%$

$27 \%$

$4 \%$

$13 \%$

Recording wildlife on farm

$26 \%$

$15 \%$

$26 \%$

\section{Percentage}

100

(= positive)-neutral, unlikely-definitely not (= negative) for participation. The majority of respondents were positive about the usefulness of activities, with their willingness to participate only slightly lower in most categories

There were several instances where significant differences could be detected between the responses from the British and French respondents. There was stronger agreement about the usefulness of the citizen science approach for data collection and real-time monitoring by British farmers (Fisher's exact

\section{Number of} respondents

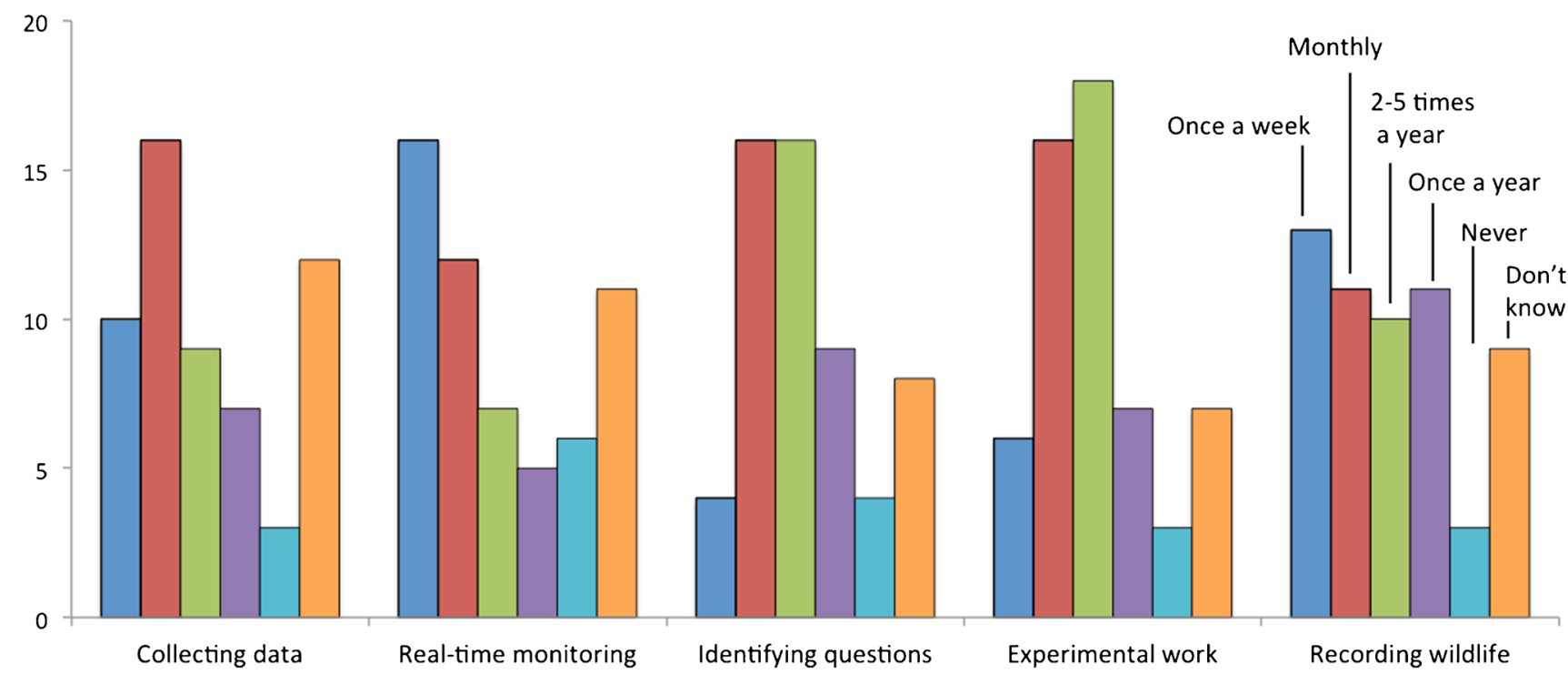

Fig. 3 Frequency of different time commitment survey respondents were willing to commit to various citizen science activities. Many respondents were willing to participate on a frequent basis with the majority saying they would take part at least monthly. Very few said that they would never participate, although uncertainty in all activities was high (indicated by the "don't know" responses) 
tests, $p=0.0052$ and $p=0.0462$, respectively). Most notable were the differences between the two countries interest in recording wildlife on farms. Half of the French respondents were unlikely or very unlikely to participate in wildlife recording, compared to British respondents who were likely to take part (Fisher's exact test, $p=0.0063$ ). When asked about the potential effort they would be willing to commit to wildlife recording, most French respondents (40\%) were only interested in a once a year commitment, whereas the majority of British respondents (54\%) would be willing to participate once a week or monthly (Fisher's exact test, $p=0.0032$ ). Similarly, there was a significant difference with regard to the financial support that may be necessary to support such work (Fisher's exact test, $p=0.0066$ ), with French respondents more likely to require financial support. One possible explanation for these differences could be a result of the translation of the English word "wildlife" to the French "faune", which relates to animals only, and which respondents may consider more difficult to record than plants for example. On the other hand, Britain has an exceptional history and tradition of recoding wildlife (Silvertown 2009), and findings could therefore be a result of cultural difference between the two countries.

\section{Conclusion}

This paper is the first to quantify and explore farmers' use of smartphones in Europe and assess the potential of smartphones for farm-based participatory research. While our results and arguments are derived from a relatively small sample, we have been able to draw some important conclusions that will help guide future research agendas concerning citizen science, mobile communication technology, and agriculture.

This paper presents data about the use of smartphone technology amongst European farmers, focusing on the British and French farming sector thus enabling us to contribute to the relatively small pool of evidence about the extent of smartphone use amongst farmers. Our results also demonstrate that there is a strong willingness amongst farmers to engage with citizen science for agricultural research. Even though, farmers were clear that some of the activities would only be possible with financial support or limited time commitment. These findings highlight the importance of citizen science projects having an applied focus, where the parameters and aims are developed in a participatory manner, to ensure that research objectives are relevant and have an applicable and practical utility for farmers "on the ground", but also the potential need to support some of the work financially. In addition to this, it is necessary to highlight that citizen science projects are also about collective benefit and smartphone applications that generate evidence about agricultural techniques, soils, and pests and diseases, for example, would enable the wider agricultural and scientific community to understand trends and problems as they arise and assist in the development and quest for solutions, both at the policy level and in scientific initiatives. This has applicability in the two countries of study, but also globally, particularly in developing countries where mobile phone ownership and use amongst rural smallholders has proliferated in recent years (Henriques and Kock 2012; van Etten 2011). However, it is important to be mindful that online connectivity and skills needed for the use of apps and social media, for example, is not a universal phenomenon amongst all demographics and geographical spaces (Bos and Owen 2016). The value of face-to-face meetings cannot be replaced by these technologies and also avoid excluding certain groups. These contextual factors must therefore be taken into account in the design of citizen science projects that utilise smartphone technologies as the main source of data production/collection.

Smartphone technologies offer great potential for participatory agricultural research and large scale data collection, and our results indicate that farmers have sufficient access to and knowledge of the technology, as well as enthusiasm for citizen science participation, providing a basis for the wider application in future participatory research projects.

Acknowledgments We are grateful to all the farmers that took part in our survey, the people and organisations that helped to recruit participants by promoting the survey link, and to Colin Anderson, Adrian Evans, and Csilla Kiss for discussions and help with the survey design and translations.

Open Access This article is distributed under the terms of the Creative Commons Attribution 4.0 International License (http:// creativecommons.org/licenses/by/4.0/), which permits use, duplication, adaptation, distribution and reproduction in any medium or format, as long as you give appropriate credit to the original author(s) and the source, provide a link to the Creative Commons license and indicate if changes were made.

\section{References}

Adriaens T, Sutton-Croft M, Owen K, Brosens D, van Valkenburg J, Kilbey D, Groom Q, Ehmig C, Thürkow F, van Hende P, Schneider K (2015) Trying to engage the crowd in recording invasive alien species in Europe: experiences from two smartphone applications in northwest Europe. Manag Biol Invasions 6(2):215225. doi:10.3391/mbi.2015.6.2.12

August T, Harvey M, Lightfoot P, Kilbey D, Papadopoulos T, Jepson P (2015) Emerging technologies for biological recording. Biol J Linn Soc 115(3):731-749. doi:10.1111/bij.12534

Bos E, Owen L (2016) 'Virtual Reconnection': the online spaces of alternative food networks in England. J R Stud 45:1-14. doi:10.1016/j. jrurstud.2016.02.016

Core Team R (2015) R: a language and environment for statistical computing. R Foundation for Statistical Computing, Vienna

CRÉDOC (2015) Le baromètre du numérique. Le Conseil Général de l'Economie (CGE) 
Dickinson JL, Zuckerberg B, Bonter DN (2010) Citizen science as an ecological research tool: challenges and benefits. Annu Rev Ecol Evol Syst 41(1):149-172. doi:10.1146/annurev-ecolsys-102209144636

Doohan D, Wilson R, Canales E, Parker J (2010) Investigating the human dimension of weed management: new tools of the trade. Weed Sci 58:503-510. doi:10.1614/WS-D-09-00086.1

Farmers Weekly (2014) 16 essential farming apps for 2014. Farmers Weekly online edition, 5.3.2014, http://www.fwi.co.uk/machinery/ 16-essential-farming-apps-for-2014.htm

Graham EA, Henderson S, Schloss A (2011) Using mobile phones to engage citizen scientists in research. Eos, Trans Am Geophys Union 92(38):313-315. doi:10.1029/2011EO380002

Henriques J, Kock B (2012) Empowering smallholders and local food markets with smartphones and social networks. IEEE Global Humanitarian Technology Conference (GHTC), Seattle, pp 181185. doi:10.1109/GHTC.2012.37

MacMillan T, Pearce B (2014) Duchy Originals Future Farming Programme - a practical, farmer led approach to innovation. IFOAM Organic World Congress 2014, Istanbul, pp 1-3

OFCOM (2015) The communication market report: United Kingdom. London

Pescott OL, Walker KJ, Pocock MJO, Jitlal M, Outhwaite CL, Cheffings CM, Harris F, Roy DB (2015) Ecological monitoring with citizen science: the design and implementation of schemes for recording plants in Britain and Ireland. Biol J Linn Soc 115(3):505-521. doi: 10.1111/bij.12581

Pongnumkul S, Chaovalit P, Surasvadi N (2015) Applications of smartphone-based sensors in agriculture: a systematic review of research. J Sensors 2015:18. doi:10.1155/2015/195308

Prager K, Thomson K (2014) AKIS and advisory services in the United Kingdom. Report for the AKIS inventory (WP3) of the PRO AKIS project. James Hutton Inst

Riddlesden D, Singleton AD (2014) Broadband speed equity: a new digital divide? Appl Geogr 52:25-33. doi:10.1016/j.apgeog.2014. 04.008

Semler J (2015) ABM AGRI Media Council's research. Agric Mark

Silvertown J (2009) A new dawn for citizen science. Trends Ecol Evol 25(9):467-471. doi:10.1016/j.tree.2009.03.017

Teacher AGF, Griffiths DJ, Hodgson DJ, Inger R (2013) Smartphones in ecology and evolution: a guide for the app-rehensive. Ecol Evol 3(16):5268-5278. doi:10.1002/ece3.888

The Economist (2015) The truly personal computer. The Economist, 28th February 2015, http://www.economist.com/news/briefing/ 21645131-smartphone-defining-technology-age-truly-personalcomputer

van Etten J (2011) Crowdsourcing crop improvement in Sub-Saharan Africa: a proposal for a scalable and inclusive approach to food security. IDS Bull 42(4):102-110. doi:10.1111/j.1759-5436.2011. 00240.x 